\title{
RESEARCH
}

Open Access

\section{Risk factors for asymptomatic malaria infections from seasonal cross-sectional surveys along the China-Myanmar border}

Yan Zhao ${ }^{1}$, Jie Zeng ${ }^{1}$, Yonghong Zhao' ${ }^{1}$ Qingyang Liu' ${ }^{1}$, Yang He ${ }^{1}$, Jiaqi Zhang ${ }^{2}$, Zhaoqing Yang ${ }^{2}$, Qi Fan ${ }^{3}$, Qinghui Wang ${ }^{1 *}$, Liwang Cui ${ }^{1,4^{*}}$ and Yaming Cao ${ }^{1 *}$ (D)

\begin{abstract}
Background: Border malaria, a shared phenomenon in the Greater Mekong Sub-region of Southeast Asia, is a major obstacle for regional malaria elimination. Along the China-Myanmar border, an additional problem arose as a result of the settlement of internally displaced people (IDP) in the border region. Since asymptomatic malaria significantly impacts transmission dynamics, assessment of the prevalence, dynamics and risk factors of asymptomatic malaria infections is necessary.
\end{abstract}

Methods: Cross-sectional surveys were carried out in 3 seasons (March and April, July and November) and 2 sites (villages and IDP camps) in 2015. A total of 1680 finger-prick blood samples were collected and used for parasite detection by microscopy and nested RT-PCR (nRT-PCR). Logistic regression models were used to explore the risk factors associated with asymptomatic malaria at individual and household levels.

Results: The prevalence of asymptomatic Plasmodium infections was $23.3 \%$ by nRT-PCR, significantly higher than that detected by microscopy (1.5\%). The proportions of Plasmodium vivax, Plasmodium falciparum and mixed-species infections were 89.6, 8.1 and 2.3\%, respectively. Asymptomatic infections showed obvious seasonality with higher prevalence in the rainy season. Logistic regression analysis identified males and school children ( $\leq 15$ years) as the high-risk populations. Vector-based interventions, including bed net and indoor residual spray, were found to have significant impacts on asymptomatic Plasmodium infections, with non-users of these measures carrying much higher risks of infection. In addition, individuals living in poorly constructed households or farther away from clinics were more prone to asymptomatic infections.

Conclusions: Sub-microscopic Plasmodium infections were highly prevalent in the border human populations from IDP camps and surrounding villages. Both individual- and household-level risk factors were identified, which provides useful information for identifying the high-priority populations to implement targeted malaria control.

Keywords: Asymptomatic infection, Plasmodium, Risk factor, Malaria, Myanmar

\footnotetext{
*Correspondence: gaihui2010@163.com; luc2@psu.edu;

ymcao@cmu.edu.cn

${ }^{1}$ Department of Immunology, College of Basic Medical Sciences, China

Medical University, Shenyang 110122, Liaoning, China

${ }^{4}$ Department of Entomology, Pennsylvania State University, University

Park, State College, PA 16802, USA

Full list of author information is available at the end of the article
} 


\section{Background}

In the past decades, intensive malaria interventions have resulted in a dramatic decline in global malaria morbidity and mortality. However, the global burden of malaria is still enormous: in 2016 there were about 216 million cases resulting in $\sim 445,000$ deaths [1]. The Global Technical Strategy for Malaria 2016-2030 was endorsed by World Health Assembly, calling for a reduction in global incidence and mortality of malaria by at least $90 \%$ by 2030 [2]. This ambitious plan should include all types of malaria infections, including severe and complicated, mild and uncomplicated, and asymptomatic infections [3, 4]. Compared with asymptomatic malaria, acute malaria infections are often quoted as the "tip of an iceberg", while the overwhelming majority of malaria infections are asymptomatic as identified by molecular methods with increasing sensitivities [5-8]. Asymptomatic carriers of malaria are prevalent in both low- and high-endemicity regions and they are important reservoirs for sustaining malaria transmission because they persist for long time and harbour gametocytes that are infectious to Anopheles mosquitoes [9-15]. With regard to infectivity of submicroscopic infections to mosquitoes, some studies have even reported that parasites from asymptomatic individuals were even more infectious to vectors than those from symptomatic cases [16-18]. Since the prevalence, dynamics and transmissibility of asymptomatic malaria vary geographically and are influenced by complex factors involving parasites, hosts and environments [19, 20], identification of these factors is particularly important for malaria control.

In the Greater Mekong Sub-region (GMS) of Southeast Asia, malaria distribution is heterogeneous and often concentrated along international borders [21-24]. Border regions are not only difficult to access, but human migration across the porous borders also poses further danger of malaria re-introduction [25]. Border malaria, a shared phenomenon of the GMS, is a major challenge for achieving the regional malaria elimination goal by 2030 [26]. It requires coordinated control efforts from neighbouring countries. Recently, the asymptomatic Plasmodium reservoir has been reported to be considerable, even in lowtransmission settings along the international borders in GMS, including Thailand-Cambodia, Thailand-Myanmar and China-Myanmar borders [8, 27, 28]. Within the GMS, Myanmar has the highest malaria burden. In addition, as a consequence of internal military conflict, refugees and internally displaced people (IDP) rushed to and settled down along the international borders. The overcrowded and poor living conditions in these camps increase the risk of infectious diseases [29-31]. In the IDP camps and the nearby villages of Kachin State at the China-Myanmar border, previous surveys have detected continued malaria transmission and observed Plasmodium vivax outbreaks in recent years [32]. The potential spillover of disease outbreaks to neighbouring communities demands strengthened control efforts and close surveillance.

With continued transmission of malaria in the ChinaMyanmar border, this study wanted to address the potential of asymptomatic Plasmodium infections as important reservoirs. The use of highly sensitive molecular detection methods allowed the detection of almost $20 \%$ of local residents as carriers of asymptomatic Plasmodium infections [8]. In the present study, further efforts were undertaken to study the seasonal dynamics and risk factors of asymptomatic malaria infections in the IDP camps and surrounding villages. Knowledge gained from this study may help identify a potential bottleneck transmission season and high-risk human populations to implement targeted radical elimination practices.

\section{Methods \\ Ethical consideration}

The study protocol was reviewed and approved by institutional review boards of China Medical University, China, Pennsylvania State University, USA and the local Health Bureau of Kachin State, Myanmar. Before carrying out the study, all adult participants or legal guardians of children voluntarily signed the informed consent.

\section{Study sites}

This study was conducted in 4 villages (MLH, L1, MSY, JHK) and 2 IDP camps (N2 and N3) near Laiza township $\left(97.56^{\circ} \mathrm{E}\right.$ and $\left.24.75^{\circ} \mathrm{N}\right)$, Kachin State, Myanmar, along the China-Myanmar border area (Fig. 1). The study sites are located in the same valley area with an elevation ranging from 200 to $550 \mathrm{~m}$ above sea level. In each of the IDP camps, there is a health clinic providing routine health services to the camp residents, while the 4 villages are served by a clinic located in Laiza town. This region has a sub-tropical climate with November to April the dry and cold months, and May to October the warm and humid months. Malaria transmission in this region is perennial and dynamic, concentrated in the rainy season [33]. Anopheles minimus s.l. is the predominant vector species complex, and adult Anopheles density on average is higher in villages than IDP camps [32].

\section{Sample and data collection}

Sample size required to detect the prevalence of asymptomatic infection in the survey sites was calculated as $\mathrm{n}=\left(\mu^{2}\right)(\pi)(1-\pi) / \delta^{2}$, using an expected asymptomatic malaria prevalence for the border $(\pi)$ of $20 \%$ [8]; $\mu$ statistic of 1.96 for $95 \%$ confidence interval (CI) and marginal error $(\delta)$ of $2 \%$. Three cross-sectional surveys were 

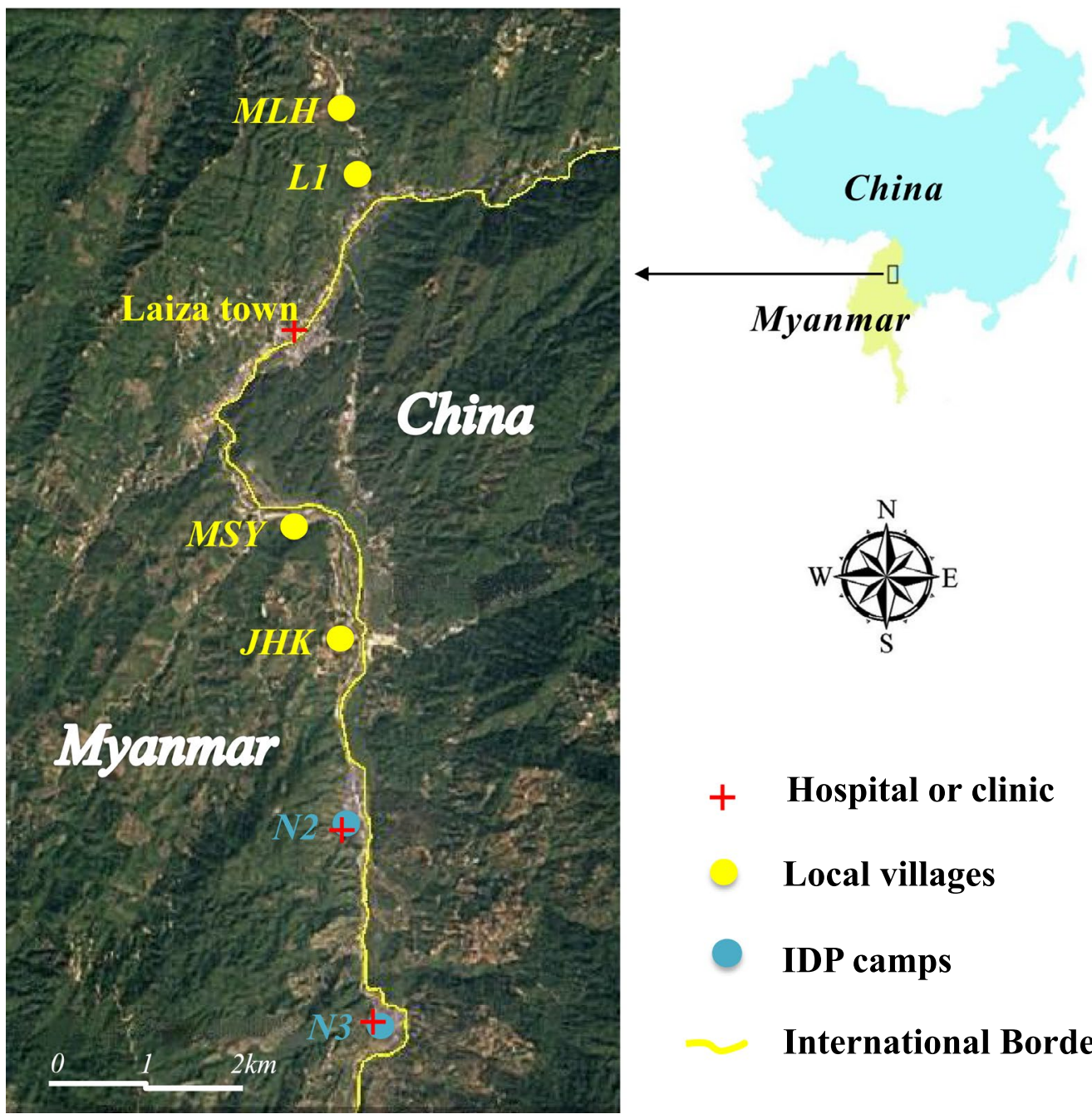

Fig. 1 Map of study area. All villages and IDP camps in the area have been mapped as yellow and blue patches, respectively. Clinics are marked by red crosses

conducted in 2015 to assess malaria prevalence in different seasons: March and April, July and November to represent the pre-peak (early), peak, and post-peak (late) seasons, respectively. To encourage participation in this study, a team comprised of nurses from the local Health Bureau visited the villages and camps to inform village leaders and camp authorities about the study. During the surveys, trained local nurses and medical technologists visited the households in the villages and IDP camps to obtain informed consent from the head of each household prior to the interview and sample collection. Instructed questionnaires were used to collect individual demographic and behavioural (gender, age, occupation, malaria history, bed net usage) and household information (education of the household head, major building material of the house, its elevation and spatial location relative to landmarks such as road, forest, water body, border, and clinic, as well as the use of indoor residual spray (IRS). Age was arbitrarily grouped into 2 categories: $\leq 15$ and $>15$ years, whereas occupation was grouped into 4 categories: students (pre-school and school children), office and in-house workers (office staff, teachers and housewives), soldiers, and farmers. The information on characteristics of households was obtained mainly from heads of household. Housewives were respondents if the heads were away at work. The distance to the indicated locations was calculated in ArcGIS 10.2. Major building material of the house was used as a proxy for the economic status of the family, as economically better families would invest on improvement of house structure with bricks in contrast to the poor living in houses or huts made of naturally available, cheaper materials 
such as wood or bamboo [34]. During the visit, axillary temperature was measured and those with temperature $\geq 37.5^{\circ} \mathrm{C}$ or a history of fever during the prior $24 \mathrm{~h}$ were referred to the nearest local health staff or clinic to receive adequate treatment and follow-up as clinically appropriate. Finger-prick blood was used to make thick and thin smears, which were air dried, transported to a nearby field laboratory, and stained with $10 \%$ Giemsa. In addition, $100 \mu \mathrm{L}$ of finger-prick blood were collected in tubes containing EDTA and transferred on ice to the laboratory, where it was mixed with $200 \mu \mathrm{L}$ Trizol reagent and stored at $-80^{\circ} \mathrm{C}$. The samples were shipped on dry ice to China Medical University for laboratory studies.

\section{Parasite detection by microscopy and nested RT-PCR}

Thick and thin blood films were screened for the presence of malaria parasites using light microscopes with $100 \times$ oil immersion lens. Two microscopists examined all slides, and when discrepancy occurred, a third microscopist read the slides and the results were combined. For RNA extraction, $1 \mathrm{~mL}$ of Trizol reagent was added to the frozen sample containing $0.1 \mathrm{~mL}$ of blood. Total RNA was isolated according to the manufacturer's protocol and dissolved in $30 \mu \mathrm{L}$ RNase-free water. One microgram of each RNA sample was used to synthesize cDNA using the Takara RNA PCR kit (AMV) version 3.0 (Takara, Japan). Parasite detection was performed by nested RTPCR (nRT-PCR) targeting the 18S rRNA using an established protocol [8], which showed a limit of detection of 0.01 parasites $/ \mu \mathrm{L}$ of blood.

\section{Statistical analysis}

Maps were generated using Google Earth. Statistical analysis was performed using SPSS Statistics 19.0. For risk factor analysis, both univariate and multivariate mixed effects logistic regression models were applied. First, explanatory variables were tested individually in univariate analysis. Then, all factors with $P<0.25$ were selected to be involved in the following multivariate analysis $[35,36]$. Potential risk factors were analysed at both individual and household levels, and only those with $P<0.05$ in multivariate analysis were considered to be the risk factors. Individual-level, independent variables included gender, age, occupation, malaria history, and bed net usage. Household-level factors included education of household head, building material of the house, IRS usage and location elevation. In addition, spatial location relative to landmarks was acquired for each household and considered household-level variables for analysis. For descriptive analyses, $\chi^{2}$ test or Fisher's exact test was used. Asymptomatic malaria prevalence for the predictive factors was compared between the rainy and dry seasons, and between villages and IDP camps using
$X^{2}$ test, and odds ratio (OR) and adjusted odds ratio (AOR) were calculated. $P<0.05$ was considered statistically significant.

\section{Results}

\section{Characteristics of the study population}

A census prior to the surveys identified the population size in the 4 study villages as 1436 . The IDP camps were established in 2011 as the result of Myanmar civil war with an initial population of $\sim 7000$, which was increased to 10,402 in 2015 with populations migrated from more interior areas of Kachin. Using the prevalence of $\sim 20 \%$ of asymptomatic infections determined using a sensitive molecular method [8], the sample size to detect malaria parasite infection prevalence was determined to be 1537 . Thus, the sample size was expanded to include 1680 healthy individuals without fever and malaria-related symptoms from 773 households, which represented 38.4\% (773/2014) of the total households (Fig. 2). Three cross-sectional surveys were conducted in early $(n=516)$, peak $(n=578)$ and late $(n=586)$ seasons. Though the census identified $48.8 \%$ of the population as males, many adult males could not be reached as they were required to be enlisted. Therefore, the surveyed population was female-biased (70.3\%). The median age of the volunteers was 33 years (95\% CI 31-34), with more than $70 \%$ participants in $>15$ age groups in each season. The majority of the participants were office and in-house workers $(54.6 \%)$, followed by students $(28.3 \%)$. When asked about their malaria histories, $3.6 \%$ of the participants self-admitted that they had malaria within the last year. With regard to preventive measures targeting vectors, participants were specifically asked for the use of bed nets. The earlier study established that bed net ownership in the study community was close to $100 \%$, but usage was $\sim 75 \%$. The current surveys identified that less than half (45.1\%) of the participants used bed nets in previous nights (Table 1). Of the 773 households surveyed, $35.4 \%$ had IRS during the previous month. The majority of the heads of the households had primary $(34.9 \%)$ or middle school (63.0\%) levels of education. With regard to the house structures and building materials, the majority of the houses were built using wood and bamboo as the main construction materials (95.2\%), whereas only 5.2\% of the houses were constructed using bricks (Table 2).

\section{Asymptomatic malaria parasite prevalence}

Microscopic examination of the 1680 blood smears only detected $P$. vivax infections in 25 samples, giving an overall $1.5 \%$ parasite prevalence. The prevalence of $P$. vivax infections in the peak season (2.3\%) was slightly higher than that of the early season (1.7\%) and late season $(1.5 \%)$, but the differences were not statistically 


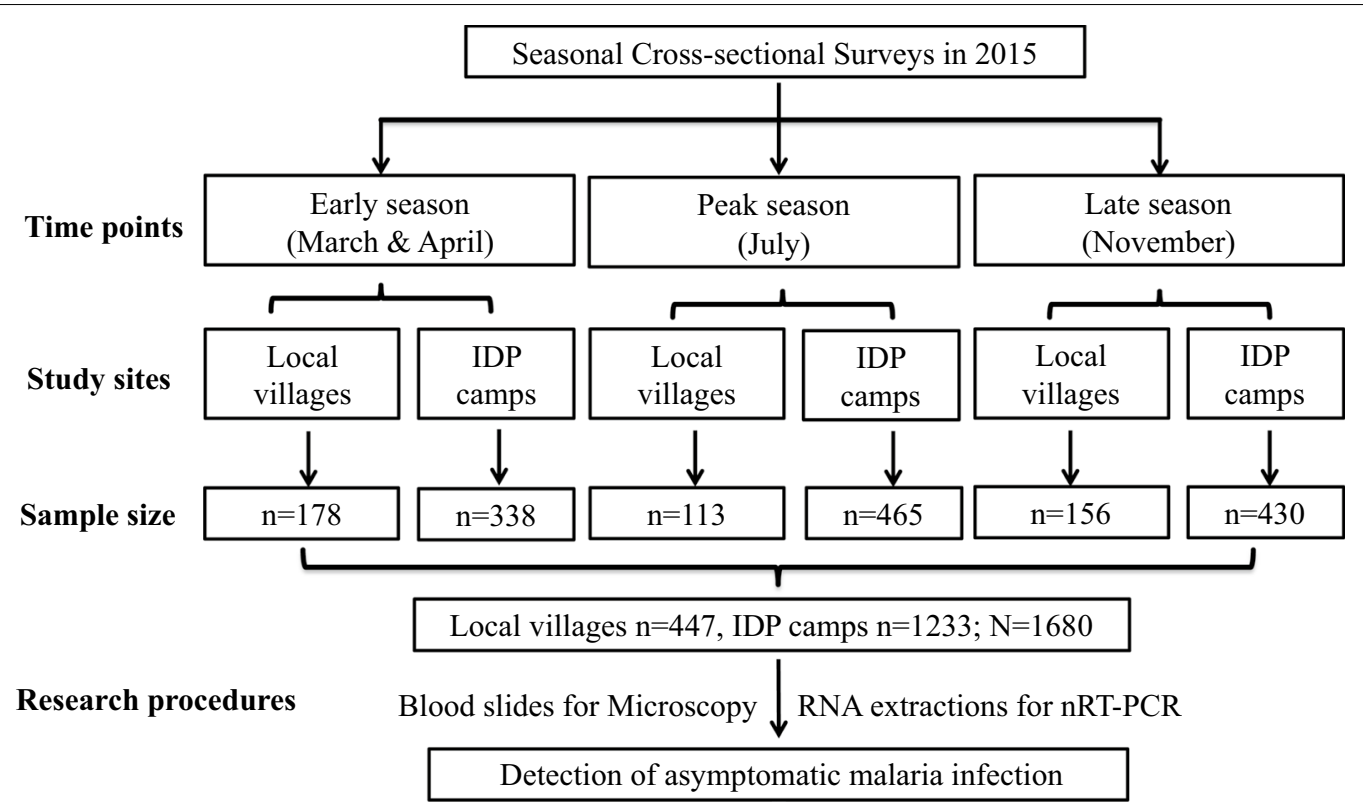

Fig. 2 Flow chart of sample collection and research procedures. $n$ number of samples, $N$ total number of samples

Table 1 Demographics of the study population [n (\%)]

\begin{tabular}{|c|c|c|c|c|}
\hline Characteristics & Early season & Peak season & Late season & Total \\
\hline Number of participants (\% male) & $516(26.0)$ & $578(36.2)$ & $586(26.6)$ & $1680(29.7)$ \\
\hline \multicolumn{5}{|l|}{ Age groups (years) } \\
\hline$\leq 15$ & $76(14.7)$ & $165(28.6)$ & $165(28.2)$ & $406(24.2)$ \\
\hline$>15$ & $440(85.3)$ & $413(71.4)$ & $421(71.8)$ & $1274(75.8)$ \\
\hline \multicolumn{5}{|l|}{ Occupation } \\
\hline Students & $96(18.6)$ & $187(32.4)$ & $192(32.8)$ & $475(28.3)$ \\
\hline Office and in-house workers & $309(59.9)$ & $285(49.3)$ & $323(55.1)$ & $917(54.6)$ \\
\hline Soldiers & $19(3.7)$ & $25(4.3)$ & $17(2.9)$ & $61(3.6)$ \\
\hline Farmers & $92(17.8)$ & $81(14.0)$ & $54(9.2)$ & $227(13.5)$ \\
\hline Malaria history (in the last year) & $39(7.6)$ & $8(1.4)$ & $13(2.2)$ & $60(3.6)$ \\
\hline Use of bed net & $266(51.6)$ & $260(45.0)$ & $237(40.4)$ & $763(45.1)$ \\
\hline
\end{tabular}

significant (Table 3). In comparison, nRT-PCR targeting the $18 \mathrm{~S}$ rRNA gene detected $23.4 \%$ (393/1680) prevalence of asymptomatic infections. Specifically, 23 of the 25 microscopy-positive samples were confirmed by nRTPCR, demonstrating that the majority (94.1\%) of the asymptomatic infections were sub-microscopic. The 393 nRT-PCR positive samples included 352 (89.6\%) Plasmodium vivax, 32 (8.1\%) Plasmodium falciparum, and 9 (2.3\%) mixed P. vivax/P. falciparum infections. Plasmodium ovale, Plasmodium malariae and Plasmodium knowlesi infections were not detected. It is noteworthy that $P$. falciparum infections were only identified in the 2 later surveys.
In contrast to the results from microscopic examination, there were significantly seasonal differences in the prevalence of infections detected by nRT-PCR $(P=0.001): 18.4 \%$ of infection occurred in early season (March-April), 30.1\% in the rainy season (July), and $21.2 \%$ in the late season (November) (Table 3 ). This seasonal variation was notably dramatic among the villagers. Prior to the rainy season, the prevalence of asymptomatic infection in the villages was relatively low at $8.43 \%$, which sharply rose to $>50 \%$ during the peak transmission season (Fig. 3). In comparison, the prevalence of sub-microscopic infections did not show substantial seasonal variation in the IDP camps (Fig. 3). Furthermore, 
Table 2 Characteristics of the study households

\begin{tabular}{lc}
\hline Education of household head [N (\%)] & $11(1.4)$ \\
Illiterate & $270(34.9)$ \\
Primary school & $487(63.0)$ \\
Middle school & $5(0.6)$ \\
High school and above & \\
Major material of house [N (\%)] & $733(95.2)$ \\
Wood/bamboo & $40(5.2)$ \\
Brick & $285(36.9)$ \\
Use of IRS [N (\%)] & $312(298-390)$ \\
Elevation (meters above sea level) [median (IQR)] & $200(31-300)$ \\
Distance to the nearest forest (m) [median (IQR)] & $180(80-250)$ \\
Distance to the nearest clinic (m) [median (IQR)] & $50(16-190)$ \\
Distance to the nearest water body (m) [median (IQR)] & $15(10-25)$ \\
Distance to the nearest road (m) [median (IQR)] & $100(45-200)$ \\
Distance to the border (m) [median (IQR)] &
\end{tabular}

$I Q R$ inter quartile range

the comparison of the asymptomatic infections between villages and IDP camps during the different seasons revealed that before the rainy season, the prevalence of asymptomatic infection in the villages $(8.43 \%)$ was significantly lower than that in the IDP camps (8.43 vs $23.7 \%$, $P<0.001)$, whereas this trend was obviously reversed in the peak transmission season ( 54.1 vs $24.5 \%, P<0.001)$. This trend was maintained after the rainy season, and the prevalence of asymptomatic infections in the villages (26.3\%) was much higher than that in the IDP camps $(19.3 \%)$ in November, though the difference was marginal $(P=0.069)$.

\section{Risk factors associated with asymptomatic malaria infections}

Univariate and multivariate analyses were performed to identify the risk factors associated with asymptomatic malaria infections. In the univariate analysis, all potential factors were tested and only those with $P$ values less than 0.25 (including gender, age, bed net use, major building material of house, IRS use, elevation, location to clinic and road) were selected and set into the final multivariate model. First, the results showed that males were significantly more likely than females to have asymptomatic infections (AOR: 1.5; 95\% CI 1.16-1.97, $P=0.002$ ). Second, the age group of $\leq 15$ had significantly higher odds of malaria infection $(\mathrm{AOR}=1.49,95 \% \mathrm{CI}=1.13-1.96$, $P=0.004)$. Third, the effects of vector control-based preventive measures were very remarkable. Those who did not sleep under the bed nets had more than 5 times higher odds of asymptomatic infections than those who did (AOR: 5.49, 95\% CI 4.12-7.32, $P<0.001$ ). People from the households that did not have IRS had 3.4 times higher odds of asymptomatic infection than those with IRS (95\% CI $2.50-4.65, P<0.001)$. Fourth, major building materials of the houses, which reflect the economic status of the family, also showed significant effect on asymptomatic infections. Residents from the houses constructed from wood or bamboo had approximately twice the odds of having Plasmodium infections (AOR: 1.90, 95\% CI 1.15$3.14, P=0.012)$. Last, longer distance of household to the nearest clinic (>180 m) was also significantly associated with a higher risk of malaria infection (AOR: 2.05, 95\% CI 1.53-2.75, $P<0.001$ ) (Table 4).

\section{Risk factors in different seasons}

To further explore whether the risk factors for asymptomatic malaria infections experience seasonal variations, the 2 surveys conducted in the dry season (March-April and November) were combined and compared with that conducted in the rainy season (July). With regard to preventive measures, those who did not use bed nets had 10.53 (95\% CI 6.38-17.40; $P<0.001)$ and 3.81 times $(95 \%$ CI 2.67-5.43, $P<0.001)$ higher odds of having asymptomatic infections than those who used bed nets in the rainy and dry season, respectively (Table 5). Moreover, those who did use bed nets in the rainy season had 2.28 times higher odds of having asymptomatic infections than those in the dry season (95\% CI 1.72-3.03,

Table 3 Prevalence of asymptomatic malaria infections in different seasons detected by microscopy and nRT-PCR

\begin{tabular}{|c|c|c|c|c|c|c|}
\hline Diagnosis & Parasite & Early [n (\%)] & Peak [n (\%)] & Late [n (\%)] & Total [n (\%)] & Pvalue $^{1}$ \\
\hline \multirow[t]{4}{*}{ Microscopy } & P. vivax & $9(1.7)$ & $13(2.3)$ & $3(0.5)$ & $25(1.5)$ & 0.066 \\
\hline & P.falciparum & 0 & 0 & 0 & 0 & - \\
\hline & Mixed infection & 0 & 0 & 0 & 0 & - \\
\hline & Total & $9(1.7)$ & $13(2.3)$ & $3(0.5)$ & $25(1.5)$ & 0.066 \\
\hline \multirow[t]{4}{*}{$n R T-P C R$} & P. vivax & $95(18.4)$ & $152(26.3)$ & 105 (17.9) & $352(21.0)$ & 0.001 \\
\hline & P. falciparum & 0 & $14(2.4)$ & $18(3.1)$ & $32(1.9)$ & $<0.001$ \\
\hline & Mixed infection & 0 & $8(1.4)$ & $1(0.2)$ & $9(0.5)$ & 0.002 \\
\hline & Total & $95(18.4)$ & $174(30.1)$ & $124(21.2)$ & $393(23.4)$ & 0.001 \\
\hline
\end{tabular}

\footnotetext{
${ }^{1}$ Chi square test or Fisher's exact test for comparison among different seasons. Significant at $P<0.05$. Mixed infection-P. falciparum and $P$. vivax
} 


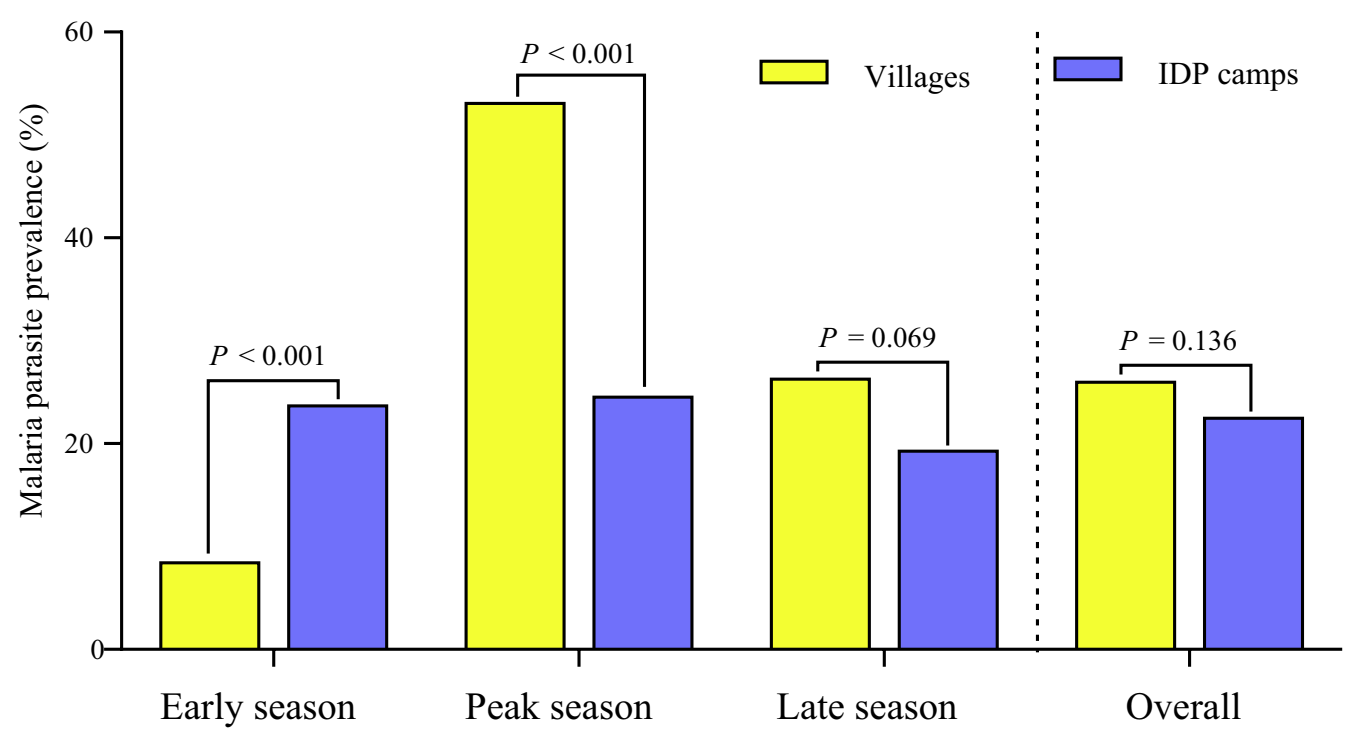

Fig. 3 Prevalence of asymptomatic malaria carriage in different study sites identified by nRT-PCR. Chi square $\left(x^{2}\right)$ test was used for assessing differences in asymptomatic malaria infection between village and IDP camp populations in three seasons. The infections included all species detected by $n R T-P C R$

Table 4 Assessment of risk factors for asymptomatic malaria infection

\begin{tabular}{|c|c|c|c|c|c|c|}
\hline Predictive factors & Category & PCR positive [n (\%)] & $\begin{array}{l}\text { Univariate } \\
\text { OR }(95 \% \mathrm{Cl})\end{array}$ & P value ${ }^{1}$ & $\begin{array}{l}\text { Multivariate } \\
\text { AOR }(95 \% \mathrm{Cl})\end{array}$ & Pvalue $^{2}$ \\
\hline \multicolumn{7}{|l|}{ Individual level } \\
\hline \multirow[t]{2}{*}{ Gender } & Male & $153(30.7)$ & $1.73(1.37,2.20)$ & $<0.001$ & $1.51(1.16,1.97)$ & 0.002 \\
\hline & Female & $240(20.3)$ & 1 & & 1 & \\
\hline \multirow[t]{2}{*}{ Age groups (years) } & $\leq 15$ & $135(33.3)$ & $1.96(1.53,2.51)$ & $<0.001$ & $1.49(1.13,1.96)$ & 0.004 \\
\hline & $>15$ & $258(20.3)$ & 1 & & 1 & \\
\hline \multirow[t]{2}{*}{ Bed net use } & No & $326(35.6)$ & $5.73(4.31,7.62)$ & $<0.001$ & $5.49(4.12,7.32)$ & $<0.001$ \\
\hline & Yes & $67(87.8)$ & 1 & & 1 & \\
\hline \multicolumn{7}{|l|}{ Household level } \\
\hline \multirow[t]{2}{*}{ Major material of house } & Wood/bamboo & $371(37.0)$ & $1.55(0.96,2.48)$ & 0.072 & $1.90(1.15,3.14)$ & 0.012 \\
\hline & Brick & $22(30.1)$ & 1 & & 1 & \\
\hline \multirow[t]{2}{*}{ Use of IRS } & No & $337(48.5)$ & $3.44(2.54,4.66)$ & $<0.001$ & $3.40(2.50,4.65)$ & $<0.001$ \\
\hline & Yes & $56(14.7)$ & 1 & & 1 & \\
\hline \multirow[t]{2}{*}{ Elevation of house (m) } & $\leq 312$ & $250(45.0)$ & $1.82(1.45,2.30)$ & $<0.001$ & $1.11(0.83,1.49)$ & 0.490 \\
\hline & $>312$ & $143(27.5)$ & 1 & & 1 & \\
\hline \multirow[t]{2}{*}{ Distance to the nearest clinic $(\mathrm{m})$} & $>180$ & $257(54.9)$ & $2.49(1.97,3.15)$ & $<0.001$ & $2.05(1.53,2.75)$ & $<0.001$ \\
\hline & $\leq 180$ & $136(22.4)$ & 1 & & 1 & \\
\hline \multirow[t]{2}{*}{ Distance to the nearest road $(\mathrm{m})$} & $\leq 15$ & $277(48.2)$ & $1.55(1.22,1.98)$ & $<0.001$ & $1.20(0.92,1.57)$ & 0.189 \\
\hline & $>15$ & $116(23.2)$ & 1 & & 1 & \\
\hline
\end{tabular}

$P C R$ polymerase chain reaction, $O R$ odds ratio, $A O R$ adjusted odds ratio, $C l$ confidence interval, IRS indoor residual spraying

$1 \mathrm{P}$ value was determined in a univariate logistic regression model

2 P value was assessed in the multivariate mixed effects logistic regression model—variables with P values $<0.25$ in the unadjusted analysis were considered

$P<0.001)$. Similarly, those without the use of IRS had 7.78 (95\% CI 4.57-13.25, $P<0.001)$ and 2.29 (95\% CI $1.54-3.40, P<0.001)$ times higher odds of infection in the rainy and dry season, respectively (Table 5), giving a rainy season/dry season risk ratio of $2.43(95 \%$ CI $1.86-3.17$, $P<0.001)$. Furthermore, larger distance $(>180 \mathrm{~m})$ of the 
Table 5 Assessment of risk factors for asymptomatic malaria infections in the rainy and dry seasons

\begin{tabular}{|c|c|c|c|c|c|c|}
\hline \multirow[t]{2}{*}{ Predictive factors } & \multirow[t]{2}{*}{ Category } & \multicolumn{2}{|c|}{ Rainy season } & \multicolumn{2}{|l|}{ Dry season } & \multirow{2}{*}{$\begin{array}{l}\text { Risk ratio }(95 \% \mathrm{CI})^{2} \\
\text { Rainy/dry seasons }\end{array}$} \\
\hline & & $\mathrm{PCR}+(\%)$ & $\operatorname{AOR}(95 \% \mathrm{Cl})^{1}$ & $\mathrm{PCR}+(\%)$ & $\operatorname{AOR}(95 \% \mathrm{Cl})^{1}$ & \\
\hline Overall & & 30.1 & & 19.9 & & $1.74(1.38-2.19)^{* * *}$ \\
\hline \multicolumn{7}{|l|}{ Individual-level } \\
\hline \multirow[t]{2}{*}{ Gender } & Male & 36.8 & $1.61(1.05-2.46)^{*}$ & 26.2 & $1.36(0.96-1.92)$ & $1.64(1.12-2.41)^{*}$ \\
\hline & Female & 26.3 & 1 & 17.6 & 1 & $1.67(1.24-2.24)^{* *}$ \\
\hline \multirow[t]{2}{*}{ Age groups (years) } & $\leq 15$ & 35.8 & $0.97(0.62-1.52)$ & 31.5 & $1.88(1.32-2.67)^{* * *}$ & $1.21(0.80-1.84)$ \\
\hline & $>15$ & 27.8 & 1 & 16.6 & 1 & $1.94(1.46-2.56)^{* * *}$ \\
\hline \multirow[t]{2}{*}{ Bed net use } & No & 48.1 & $10.53(6.38-17.40)^{* * *}$ & 28.9 & $3.81(2.67-5.43)^{* * *}$ & $2.28(1.72-3.03)^{* * *}$ \\
\hline & Yes & 8.1 & 1 & 9.2 & 1 & $0.87(0.51-1.50)$ \\
\hline \multicolumn{7}{|l|}{ Household-level } \\
\hline \multirow[t]{2}{*}{ Major material of house } & Wood/bamboo & 30.1 & - & 20.6 & $2.15(1.16-4.0)^{*}$ & $1.66(1.31-2.10)^{* * *}$ \\
\hline & Brick & 31.0 & 1 & 12.9 & 1 & $3.05(1.15-8.11)^{*}$ \\
\hline \multirow[t]{2}{*}{ Use of IRS } & No & 42.3 & $7.78(4.57-13.25)^{* * *}$ & 23.2 & $2.29(1.54-3.40)^{* * *}$ & $2.43(1.86-3.17)^{* * *}$ \\
\hline & Yes & 9.7 & 1 & 11.4 & 1 & $0.84(0.47-1.49)$ \\
\hline \multirow[t]{2}{*}{ Elevation of house (m) } & $\leq 312$ & 35.8 & $1.15(0.75-1.76)$ & 24.7 & $1.56(1.09-2.23)^{*}$ & $1.71(1.26-2.31)^{* *}$ \\
\hline & $>312$ & 24.1 & 1 & 15.1 & 1 & $1.88(1.30-2.71)^{* *}$ \\
\hline \multirow[t]{2}{*}{ Distance to the nearest clinic (m) } & $\leq 180$ & 21.8 & 1 & 12.8 & 1 & $1.91(1.31-2.77)^{* *}$ \\
\hline & $>180$ & 37.9 & $1.90(1.16-3.11)^{*}$ & 28.0 & $2.62(1.78-3.87)^{* * *}$ & $1.57(1.16-2.13)^{* *}$ \\
\hline \multirow[t]{2}{*}{ Distance to the nearest road (m) } & $\leq 15$ & 33.2 & $1.16(0.76-1.78)$ & 22.6 & $1.48(1.05-2.08)^{*}$ & $1.21(1.29-2.26)^{* * *}$ \\
\hline & $>15$ & 25.0 & 1 & 15.1 & 1 & $1.87(1.24-2.81)^{* *}$ \\
\hline
\end{tabular}

$P C R+P C R$ positive, $A O R$ adjusted odds ratio, $C l$ confidence interval, IRS indoor residual spray

${ }^{1}$ Multivariate logistic regression model was used for mixed effected risk factors analysis

2 Prevalence of asymptomatic malaria for predictive factors were compared between rainy season and dry seasons by using the Chi square $\left(X^{2}\right)$ test

${ }^{*} P<0.05 ;{ }^{* *} P<0.01 ;{ }^{* * *} P<0.001$

household to the nearest clinic was significantly associated with a higher risk of malaria infections in both seasons. For other factors, there were also seasonal variations. Whereas the male gender had increased odds of asymptomatic infections in the rainy season, the factor did not seem to contribute to higher infection prevalence in the dry season (Table 5). Also, people who were $\leq 15$ years and lived in houses constructed with wood/ bamboo, which were located in lower elevation $(\leq 312 \mathrm{~m}$ above sea level) and closer to road $(\leq 15 \mathrm{~m})$ had higher odds of having asymptomatic infections only in the dry season.

\section{Risk factors in villages versus IDP camps}

Further comparison of the risk factors for asymptomatic malaria infections revealed additional differences between the villages and IDP camps (Table 6). Although people who did not use bed nets from villages and camps all had increased odds of having asymptomatic Plasmodium infections compared to bed net users, those non-users from the camps had much higher odds of asymptomatic infections (AOR: 7.37, 95\% CI 5.15-10.53, $P<0.001$ ) than the non-users from the villages (AOR: $2.65,95 \%$ CI 1.61-4.35, $P<0.001)$. Similarly, IRS use also significantly reduced the odds of asymptomatic infections in households from both villages and camps, but the effect appeared more profound in the villages (Table 6). Also, larger distance $(>180 \mathrm{~m})$ of the houses to the nearest clinics was significantly associated with higher risks of malaria infections both in villages and camps. There were also village- or camp-specific risk factors. For example, lower house elevation $(\leq 312 \mathrm{~m}$ above sea level) was significantly associated with higher odds of asymptomatic malaria infection in villages, whereas there were obvious associations of the male gender and the $\leq 15$ age group with higher risks of asymptomatic infections in IDP camps.

\section{Discussion}

Asymptomatic malaria was once thought the 'forgotten' malaria, but it is a major gametocyte reservoir to conduce mosquito infection and thus a major barrier for malaria elimination [37]. In addition to the complicated features of border malaria observed elsewhere, settlements for refugees and IDP along the borders add another layer of complexity to the existing border malaria problem. This study provided further evidence about the significance of asymptomatic malaria as the reservoir for continuous 
Table 6 Assessment of risk factors for asymptomatic malaria infections between villages and IDP camps

\begin{tabular}{|c|c|c|c|c|c|c|}
\hline \multirow[t]{2}{*}{ Predictive factors } & \multirow[t]{2}{*}{ Category } & \multicolumn{2}{|l|}{ Villages } & \multicolumn{2}{|l|}{ IDP camps } & \multirow{2}{*}{$\begin{array}{l}\text { Risk ratio }(95 \% \mathrm{Cl})^{2} \\
\text { Villages/IDP camps }\end{array}$} \\
\hline & & $\mathrm{PCR}+(\%)$ & AOR $(95 \% \mathrm{CI})^{1}$ & $\mathrm{PCR}+(\%)$ & AOR $(95 \% \mathrm{Cl})^{1}$ & \\
\hline Overall & & 26.0 & & 22.5 & & $1.21(0.94-1.55)$ \\
\hline \multicolumn{7}{|l|}{ Individual-level } \\
\hline \multirow[t]{2}{*}{ Gender } & Male & 31.9 & $1.36(0.77-2.40)$ & 30.0 & $1.55(1.06-2.26)^{*}$ & $1.10(0.73-1.63)$ \\
\hline & Female & 22.4 & 1 & 19.7 & 1 & $1.18(0.85-1.63)$ \\
\hline \multirow[t]{2}{*}{ Age groups (years) } & $\leq 15$ & 32.5 & $1.47(0.80-2.70)$ & 33.4 & $1.48(1.03-2.14)^{*}$ & $0.96(0.57-1.62)$ \\
\hline & $>15$ & 24.5 & 1 & 18.5 & 1 & $1.43(1.07-1.91)^{*}$ \\
\hline \multirow[t]{2}{*}{ Bed net use } & No & 32.4 & $2.65(1.61-4.35)^{* * *}$ & 37.0 & $7.37(5.15-10.53)^{* * *}$ & $0.82(0.61-1.10)$ \\
\hline & Yes & 15.1 & 1 & 7.0 & 1 & $2.34(1.38-3.97)^{* *}$ \\
\hline \multicolumn{7}{|l|}{ Household-level } \\
\hline \multirow[t]{2}{*}{ Major material of house } & Wood/bamboo & 29.56 & - & 22.46 & - & $1.46(1.10-1.92)^{* *}$ \\
\hline & Brick & 16.92 & 1 & - & 1 & - \\
\hline \multirow[t]{2}{*}{ Use of IRS } & No & 34.4 & $8.70(3.82-19.79)^{* * *}$ & 27.2 & $2.67(1.90-3.77)^{* * *}$ & $1.40(1.06-1.85)^{*}$ \\
\hline & Yes & 5.4 & 1 & 12.4 & 1 & $0.40(0.18-0.91)^{*}$ \\
\hline \multirow[t]{2}{*}{ Elevation of house (m) } & $\leq 312$ & 33.4 & $3.42(1.51-7.72)^{* *}$ & 25.6 & $0.70(0.48-1.01)$ & $1.46(1.08-1.97)^{*}$ \\
\hline & $>312$ & 8.3 & 1 & 19.8 & 1 & $0.37(0.19-0.70)^{* *}$ \\
\hline \multirow[t]{2}{*}{ Distance to the nearest clinic (m) } & $\leq 180$ & 13.2 & 1 & 16.4 & 1 & $0.77(0.49-1.24)$ \\
\hline & $>180$ & 35.4 & $2.63(1.47-4.71)^{* *}$ & 19.9 & $2.51(1.69-3.74)^{* * *}$ & $1.29(0.94-1.76)$ \\
\hline \multirow[t]{2}{*}{ Distance to the nearest road (m) } & $\leq 15$ & 28.4 & - & 25.4 & - & $1.16(0.86-1.58)$ \\
\hline & $>15$ & 21.8 & 1 & 17.5 & 1 & $1.32(0.85-2.05)$ \\
\hline
\end{tabular}

$P C R+P C R$ positive, $A O R$ adjusted odds ratio, $C l$ confidence interval, IRS indoor residual spray

${ }^{1}$ Multivariate logistic regression model was used for mixed effected risk factors analysis

2 Infection rate of asymptomatic malaria for predictive factors were compared between local villages and IDP camps by using the Chi square $\left(X^{2}\right)$ test

${ }^{*} P<0.05 ;{ }^{* *} P<0.01 ;{ }^{* * *} P<0.001$

malaria transmission, and also identified the individual- and household-level factors associated with asymptomatic malaria infection along the China-Myanmar border. This study found increased risks of asymptomatic infections in (1) males, (2) children ( $\leq 15$ years), (3) those who failed to use bed net and IRS, (4) those who lived in poor houses, and (5) those lived farther away from a clinic. These findings provide the needed knowledge for guiding the malaria control and elimination program in border regions and in IDP camps.

Routine microscopy with a detection limit of 50-100 parasites $/ \mu \mathrm{L}$ severely underestimates the burden of asymptomatic infections [38]. In this study, nRTPCR was confirmed to be a more sensitive technique for identification of asymptomatic Plasmodium infections, revealing more than 15 -fold higher prevalence of asymptomatic infections than microscopy. The results were consistent with those from other parts of GMS such as Thailand and Cambodia [39-41], which showed that the majority of the asymptomatic infections were sub-microscopic. Despite that the prevalence was lower than in hyper-endemic regions in Africa [42, 43], the $>20 \%$ prevalence of vivax infection is astounding and may explain the persistence and outbreaks of acute vivax malaria in this region. Like the acute malaria incidence detected from passive case surveillance [24, 32], asymptomatic malaria along the border also exhibited seasonal variation. Compared with the dry season, the higher odds of infection during the rainy season might be related to increased density and species richness of the vectors [44, 45]. Interestingly, seasonal variation was more obvious in the villages, which might be related to the different vector ecology and control efforts in villages and camps [32].

Among the demographic factors, male gender and young children ( $\leq 15$ years) were significantly associated with asymptomatic infections. Such a gender bias of malaria infection has been reported in other studies [19, 46-49]. In this case, males were mostly farmers and soldiers, who are engaged in more agricultural and forestrelated activities, which might increase the chances of infection [50]. Age is considered one of the most important factors associated with protective immune response in malaria endemic areas. Many previous studies revealed adults are asymptomatic parasite carriers because they have acquired strong immunity from repeated exposures to malaria parasites, whereas infections in young children are symptomatic because their anti-malarial immunity is still developing [51-53]. Thus, the finding that school 
children ( $\leq 15$ years) had higher odds of asymptomatic malaria infections seems contradictory to findings from Africa. Yet, this finding corroborated our earlier studies, which showed that school children had increased odds of having acute vivax malaria [32, 33]. Consistent results were also obtained from a series of recent studies revealing that school-age children were an under-recognized reservoir of malaria infection showing either higher levels of asymptomatic infection or gametocyte carriage [54-56]. Such higher prevalence of asymptomatic infections in school-age children might be resulted from increased Plasmodium exposure due to neglected bed net use and drug treatment. A study conducted in Papua New Guinea showed that immunity to $P$. vivax may be acquired at a younger age than that seen with $P$. falciparum [57], which might be another reason for what was observed in this study. This highlights that malaria control initiatives should specifically target school children for malaria elimination along the border.

Malaria transmission is mainly influenced by two key factors: gametocyte infectivity and vector density. Thus, effective vector-based malaria control measures such as the use of IRS and bed nets, especially long-lasting insecticide-treated nets (LLINs) are particularly important in reducing malaria incidence [58]. This study found that non-users of bed net or IRS had much higher risks of asymptomatic malaria infection in whichever seasons or sites. Moreover, the risk was much higher in rainy season than in dry season. Additionally, odds in the surrounding villages were 2.34 times higher than those in the IDP camps, which may be largely due to higher vector densities in villages $[32,44]$. This result was in line with the higher asymptomatic malaria infection rates in local villages than in IDP camps in the peak transmission season [31, 32, 59]. Vector control interventions were insufficient in local villages as compared to those in the IDP camps, as the latter were helped by multiple nongovernmental agencies. Bed nets in local villages were mostly conventional ( $>99 \%$ ), whereas $>60 \%$ of the nets in the IDP camps were LLINs, and more frequent IRS were performed in the IDP camps during the rainy season [32]. Interestingly, such a trend of asymptomatic infections was reversed in the early dry season, when mosquito density is low. Although reasons for this are not clear, it is possible that the higher asymptomatic infection rate in the IDP camps might be due to migration of human populations from more interior areas with higher malaria endemicity as the camp population grew $[29,30]$. This study emphasized the importance of vector control strategies in reducing asymptomatic infections.

This study also found that household and the surrounding environmental factors affected the prevalence of asymptomatic malaria. Firstly, houses constructed with wood or bamboo increased the risks of infection, corroborating findings from other studies [60-62]. Since the house structures reflect the socio-economic status of the family, it may correlate with the use of personal protection measures [63, 64]. Interestingly, longer distance to the clinic is another factor associated with increased asymptomatic infections. The distance from residents in JHK and MSY villages to the nearest clinic is almost $1500 \mathrm{~m}$, and half of the recruited populations from these 2 villages were infected. One reason might be due to potential delays for patients from these 2 villages to seek treatment, especially during the rainy season when short travel becomes prohibitive due to poor road conditions [65]. Other factors associated with the locations of the houses likely reflect the surrounding environment. For example, the higher prevalence of infections in these 2 villages might be due to their closer proximity to forest edges, where mosquito vectors associated with forested areas are more abundant as shown from the earlier study [32].

The findings of these 3 seasonal cross-sectional surveys have provided insights about persistent malaria transmission along the China-Myanmar border, which is needed for malaria elimination on both sides of the border. A sensitive molecular method verified the presence of a large submicroscopic reservoir of malaria parasites in both village and IDP populations. This study also identified risk factors associated with increased prevalence of asymptomatic infections in both populations. On the individual level, males, school children, and those who did not use bed net were the as high-risk populations. On the household level, worse living conditions, failure to use the mosquito control-based interventions and farther away from the clinic were also associated with increased risks of parasite infections. While increasing the coverage of effective malaria interventions will be the key to control border malaria, additional measures such as mass drug administration (MDA) may be considered in order to reduce the infected population. MDA with chloroquine and primaquine has been found to be successful in eliminating vivax malaria in central China [66]. Furthermore, better management of malaria cases such as the recently described '1-3-7' strategy is needed in the final phase of malaria elimination [67].

This study has several limitations. First, the data collection was confined to the available residents in the households, which led to the female-biased study population and over-representation (54.6\%) of office/in-house workers, which undermines the generalization of the findings. Given that males, farmers and soldiers might be the high-risk populations, future studies should ensure a better representation of the study population. Second, the use of convenience samples inevitably adds additional 
biases, and future study designs need to be more systematic. Third, the study did not take into account the effect of human migration on malaria transmission. It is important to find out whether and how much migration of people from more malaria-endemic interior areas to the camps contributes to the malaria transmission. Furthermore, the significance of cross-border migration for malaria importation to the neighbouring Yunnan province of China also deserves special attention. Finally, the comparison between the local villages and camps needs to be more quantitative since their accesses to malaria treatment and prevention services were different. Because the whole region is targeted for malaria elimination, provision of quality malaria control services to the entire populations will ensure achieving the goal.

\section{Conclusions}

This study underscores the need for strong initiatives to control border asymptomatic malaria. Results from this study provide the needed knowledge to the malaria managers for defining the priority populations and areas for more intensified control efforts. Particularly, vector-based control measures such as bed nets and IRS appeared to provide significant protection against asymptomatic infections, and thus attention is needed to increase the coverage of these measures.

\section{Abbreviations \\ IDP: internally displaced people; IRS: indoor residual spraying; PCR: polymerase chain reaction; $\mathrm{nRT}$-PCR: nested reverse transcription PCR; OR: odds ratio; AOR: adjusted odds ratio; $95 \% \mathrm{Cl}$ : 95\% confidence interval; IQR: inter quartile range.}

\section{Authors' contributions}

YZ planned and performed the field and experimental work and analyzed data and engaged in drafting manuscript. JZ, YHZ and JQZ participated in field and experimental work. QL, YH and ZY participated in data analysis. YC, LC, QW and QF conceived the study and commented on the manuscript. All authors read and approved the final manuscript.

\section{Author details \\ ${ }^{1}$ Department of Immunology, College of Basic Medical Sciences, China Medi- cal University, Shenyang 110122, Liaoning, China. ${ }^{2}$ Department of Pathogen Biology and Immunology, Kunming Medical University, Kunming, China. ${ }^{3}$ Dalian Institute of Biotechnology, Dalian, Liaoning, China. ${ }^{4}$ Department of Entomology, Pennsylvania State University, University Park, State College, PA 16802, USA.}

\section{Acknowledgements}

We are indebted to all the volunteers from local villages and IDP camps for their willingness to take part in this study. We thank the nurses from the Kachin Health Bureau and field workers for their assistance to complete the field surveys and sample collection. We also thank the reviewers for their constructive comments and suggestions.

\section{Competing interests}

The authors declare that they have no competing interests.

\section{Availability of data and materials}

All datasets are presented in the main paper.

\section{Consent for publication}

Not applicable.

\section{Ethics approval and consent to participate}

The study protocol was reviewed and approved by institutional review boards of China Medical University, China, Pennsylvania State University, USA and the local Bureau Health of Kachin State, Myanmar. Before carrying out the study, all adult participants or legal guardians of children voluntarily signed the informed consent.

\section{Funding}

This study was supported by a grant from the National Institute of Allergy and Infectious Diseases, National Institutes of Health (2U19A1089672) and the Liaoning Natural Science Foundation (2015020747).

\section{Publisher's Note}

Springer Nature remains neutral with regard to jurisdictional claims in published maps and institutional affiliations.

Received: 3 April 2018 Accepted: 22 June 2018

Published online: 04 July 2018

References

1. WHO. World malaria report 2017. Geneva: World Health Organization; 2017.

2. Committee WHOMPA, Secretariat. Malaria Policy Advisory Committee to the $\mathrm{WHO}$ : conclusions and recommendations of seventh biannual meeting (March 2015). Malar J. 2015;14:295

3. Marsh K, Forster D, Waruiru C, Mwangi I, Winstanley M, Marsh V, et al. Indicators of life-threatening malaria in African children. N Engl J Med. 1995:332:1399-404.

4. Imbert P, Gerardin P, Rogier C, Ka AS, Jouvencel P, Brousse V, et al. Severe falciparum malaria in children: a comparative study of 1990 and 2000 WHO criteria for clinical presentation, prognosis and intensive care in Dakar, Senegal. Trans R Soc Trop Med Hyg. 2002;96:278-81.

5. Tadesse FG, van den Hoogen L, Lanke K, Schildkraut J, Tetteh K, Aseffa A et al. The shape of the iceberg: quantification of submicroscopic Plasmodium falciparum and Plasmodium vivax parasitaemia and gametocytaemia in five low endemic settings in Ethiopia. Malar J. 2017;16:99.

6. Imwong M, Hanchana S, Malleret B, Renia L, Day NP, Dondorp A, et al. High-throughput ultrasensitive molecular techniques for quantifying low-density malaria parasitemias. J Clin Microbiol. 2014;52:3303-9.

7. Hofmann N, Mwingira F, Shekalaghe S, Robinson LJ, Mueller I, Felger I. Ultra-sensitive detection of Plasmodium falciparum by amplification of multi-copy subtelomeric targets. PLoS Med. 2015;12:e1001788.

8. Zhao Y, LV Y, Liu F, Wang Q, Li P, Zhao Z, et al. Comparison of methods for detecting asymptomatic malaria infections in the China-Myanmar border area. Malar J. 2017;16:159.

9. Lennon SE, Miranda A, Henao J, Vallejo AF, Perez J, Alvarez A, et al. Malaria elimination challenges in Mesoamerica: evidence of submicroscopic malaria reservoirs in Guatemala. Malar J. 2016:15:441.

10. Zoghi S, Mehrizi AA, Raeisi A, Haghdoost AA, Turki H, Safari R, et al. Survey for asymptomatic malaria cases in low transmission settings of Iran under elimination programme. Malar J. 2012;11:126.

11. Stresman GH, Baidjoe AY, Stevenson J, Grignard L, Odongo W, Owaga C, et al. Focal screening to identify the subpatent parasite reservoir in an area of low and heterogeneous transmission in the Kenya Highlands. J Infect Dis. 2015;212:1768-77.

12. Sturrock HJ, Hsiang MS, Cohen JM, Smith DL, Greenhouse B, Bousema T, et al. Targeting asymptomatic malaria infections: active surveillance in control and elimination. PLoS Med. 2013;10:e1001467.

13. Tadesse FG, Slater HC, Chali W, Teelen K, Lanke K, Belachew M, et al. The relative contribution of symptomatic and asymptomatic Plasmodium vivax and Plasmodium falciparum infections to the infectious reservoir in a low-endemic setting in Ethiopia. Clin Infect Dis. 2018;66:1883-91.

14. Lin JT, Saunders DL, Meshnick SR. The role of submicroscopic parasitemia in malaria transmission: what is the evidence? Trends Parasitol. 2014;30:183-90. 
15. Kiattibutr K, Roobsoong W, Sriwichai P, Saeseu T, Rachaphaew N, Suansomjit C, et al. Infectivity of symptomatic and asymptomatic Plasmodium vivax infections to a Southeast Asian vector, Anopheles dirus. Int J Parasitol. 2017:47:163-70.

16. Gouagna LC, Ferguson HM, Okech BA, Killeen GF, Kabiru EW, Beier JC, et al. Plasmodium falciparum malaria disease manifestations in humans and transmission to Anopheles gambiae: a field study in Western Kenya. Parasitology. 2004;128:235-43.

17. Ouedraogo AL, Bastiaens GJ, Tiono AB, Guelbeogo WM, Kobylinski KC, Ouedraogo A, et al. Efficacy and safety of the mosquitocidal drug ivermectin to prevent malaria transmission after treatment: a double-blind, randomized, clinical trial. Clin Infect Dis. 2015;60:357-65.

18. Schneider P, Bousema JT, Gouagna LC, Otieno $S$, van de Vegte-Bolmer M, Omar SA, et al. Submicroscopic Plasmodium falciparum gametocyte densities frequently result in mosquito infection. Am J Trop Med Hyg. 2007;76:470-4.

19. Cotter C, Sturrock HJ, Hsiang MS, Liu J, Phillips AA, Hwang J, et al. The changing epidemiology of malaria elimination: new strategies for new challenges. Lancet. 2013;382:900-11.

20. Laishram DD, Sutton PL, Nanda N, Sharma VL, Sobti RC, Carlton JM, et al. The complexities of malaria disease manifestations with a focus on asymptomatic malaria. Malar J. 2012;11:29.

21. Cui L, Yan G, Sattabongkot J, Cao Y, Chen B, Chen X, et al. Malaria in the Greater Mekong Subregion: heterogeneity and complexity. Acta Trop. 2012;121:227-39.

22. Parker DM, Carrara VI, Pukrittayakamee S, McGready R, Nosten FH. Malaria ecology along the Thailand-Myanmar border. Malar J. 2015;14:388.

23. Wongsrichanalai C, Sirichaisinthop J, Karwacki JJ, Congpuong K, Miller RS, Pang $L$, et al. Drug resistant malaria on the Thai-Myanmar and Thai-Cambodian borders. Southeast Asian J Trop Med Public Health. 2001;32:41-9.

24. Hu Y, Zhou G, Ruan Y, Lee MC, Xu X, Deng S, et al. Seasonal dynamics and microgeographical spatial heterogeneity of malaria along the ChinaMyanmar border. Acta Trop. 2016;157:12-9.

25. Lo E, Zhou G, Oo W, Lee MC, Baum E, Felgner PL, et al. Molecular inference of sources and spreading patterns of Plasmodium falciparum malaria parasites in internally displaced persons settlements in Myanmar-China border area. Infect Genet Evol. 2015;33:189-96.

26. Wangdi K, Gatton ML, Kelly GC, Clements AC. Cross-border malaria: a major obstacle for malaria elimination. Adv Parasitol. 2015;89:79-107.

27. Imwong M, Nguyen TN, Tripura R, Peto TJ, Lee SJ, Lwin KM, et al. The epidemiology of subclinical malaria infections in South-East Asia: findings from cross-sectional surveys in Thailand-Myanmar border areas, Cambodia, and Vietnam. Malar J. 2015;14:381.

28. Parker DM, Matthews SA, Yan G, Zhou G, Lee MC, Sirichaisinthop J, et al. Microgeography and molecular epidemiology of malaria at the Thailand-Myanmar border in the malaria pre-elimination phase. Malar J. 2015;14:198.

29. Polonsky JA, Ronsse A, Ciglenecki I, Rull M, Porten K. High levels of mortality, malnutrition, and measles, among recently-displaced Somali refugees in Dagahaley camp, Dadaab refugee camp complex, Kenya, 2011. Confl Health. 2013;7:1.

30. Turner C, Turner P, Carrara V, Burgoine K, Tha Ler Htoo S, Watthanaworawit $W$, et al. High rates of pneumonia in children under 2 years of age in a South East Asian refugee population. PLoS ONE. 2013;8:e54026.

31. Hershey CL, Doocy S, Anderson J, Haskew C, Spiegel P, Moss WJ. Incidence and risk factors for Malaria, pneumonia and diarrhea in children under 5 in UNHCR refugee camps: a retrospective study. Confl Health. 2011;5:24.

32. Zhou G, Lo E, Zhong D, Wang X, Wang Y, Malla S, et al. Impact of interventions on malaria in internally displaced persons along the China-Myanmar border: 2011-2014. Malar J. 2016;15:471.

33. Li N, Parker DM, Yang Z, Fan Q, Zhou G, Ai G, et al. Risk factors associated with slide positivity among febrile patients in a conflict zone of northeastern Myanmar along the China-Myanmar border. Malar J. 2013;12:361.

34. Vyas S, Kumaranayake L. Constructing socio-economic status indices: how to use principal components analysis. Health Policy Plan. 2006;21:459-68.

35. Hosmer DW Jr, Lemeshow S, Sturdivant RX. Model-building strategies and methods for logistic regression. Applied logistic regression. New York: Wiley; 2013. p. 89-151.
36. Grange L, Loucoubar C, Telle O, Tall A, Faye J, Sokhna C, et al. Risk factors for Plasmodium falciparum gametocyte positivity in a longitudinal cohort. PLOS ONE. 2015:10:e0123102.

37. Alves FP, Gil LH, Marrelli MT, Ribolla PE, Camargo EP, Da Silva LH. Asymptomatic carriers of Plasmodium spp. as infection source for malaria vector mosquitoes in the Brazilian Amazon. J Med Entomol. 2005;42:777-9.

38. Bousema T, Okell L, Felger I, Drakeley C. Asymptomatic malaria infections: detectability, transmissibility and public health relevance. Nat Rev Microbiol. 2014;12:833-40.

39. Baum E, Sattabongkot J, Sirichaisinthop J, Kiattibutr K, Jain A, Taghavian $\mathrm{O}$, et al. Common asymptomatic and submicroscopic malaria infections in Western Thailand revealed in longitudinal molecular and serological studies: a challenge to malaria elimination. Malar J. 2016;15:333.

40. Durnez L, Pareyn M, Mean V, Kim S, Khim N, Menard D, et al. Identification and characterization of areas of high and low risk for asymptomatic malaria infections at sub-village level in Ratanakiri, Cambodia. Malar J. 2018;17:27.

41. Baum E, Sattabongkot J, Sirichaisinthop J, Kiattibutr K, Davies DH, Jain A, et al. Submicroscopic and asymptomatic Plasmodium falciparum and Plasmodium vivax infections are common in western Thailand-molecular and serological evidence. Malar J. 2015;14:95.

42. Sumari D, Mugasa J, Selemani M, Shekalaghe S, Mugittu K, Gwakisa P. Prevalence of submicroscopic Plasmodium falciparum infections in asymptomatic children in low transmission settings in Bagamoyo, Tanzania. MWJ. 2016;7:6.

43. Mvumbi DM, Bobanga TL, Melin P, De Mol P, Kayembe JM, Situakibanza $\mathrm{HN}$, et al. High prevalence of Plasmodium falciparum infection in asymptomatic individuals from the Democratic Republic of the Congo. Malar Res Treat. 2016;2016:5405802.

44. Wang Y, Zhong D, Cui L, Lee MC, Yang Z, Yan G, et al. Population dynamics and community structure of Anopheles mosquitoes along the ChinaMyanmar border. Parasit Vectors. 2015;8:445.

45. Kristan M, Abeku TA, Beard J, Okia M, Rapuoda B, Sang J, et al. Variations in entomological indices in relation to weather patterns and malaria incidence in East African highlands: implications for epidemic prevention and control. Malar J. 2008;7:231.

46. Sturrock HJ, Novotny JM, Kunene S, Dlamini S, Zulu Z, Cohen JM, et al. Reactive case detection for malaria elimination: real-life experience from an ongoing program in Swaziland. PLoS ONE. 2013;8:e63830.

47. Lansang MA, Belizario VY, Bustos MD, Saul A, Aguirre A. Risk factors for infection with malaria in a low endemic community in Bataan, the Philippines. Acta Trop. 1997;63:257-65.

48. Kleinschmidt I, Sharp B. Patterns in age-specific malaria incidence in a population exposed to low levels of malaria transmission intensity. Trop Med Int Health. 2001;6:986-91.

49. Monteiro TH, Chaves Tdo S, Matos HJ, Sofffiatti NF, Guimaraes RJ, Guimaraes $\mathrm{LH}$, et al. Basic sanitation, socioeconomic conditions, and degree of risk for the presence and maintenance of malaria in a low-transmission area in the Brazilian Amazon. Rev Soc Bras Med Trop. 2015;48:573-9.

50. Quantick O, Howlett-Shipley R, Roughton S, Ross D. Malaria in British military personnel deployed to Sierra Leone: a case series. J R Army Med Corps. 2017;163:65-7.

51. Lindblade KA, Steinhardt L, Samuels A, Kachur SP, Slutsker L. The silent threat: asymptomatic parasitemia and malaria transmission. Expert Rev Anti Infect Ther. 2013;11:623-39.

52. Doolan DL, Dobano C, Baird JK. Acquired immunity to malaria. Clin Microbiol Rev. 2009;22:13-36.

53. Jagannathan $P$, Muhindo MK, Kakuru A, Arinaitwe E, Greenhouse B, Tappero J, et al. Increasing incidence of malaria in children despite insecticide-treated bed nets and prompt anti-malarial therapy in Tororo, Uganda. Malar J. 2012;11:435.

54. Chourasia MK, Raghavendra K, Bhatt RM, Swain DK, Valecha N, Kleinschmidt I. Burden of asymptomatic malaria among a tribal population in a forested village of central India: a hidden challenge for malaria control in India. Public Health. 2017;147:92-7.

55. Coalson JE, Walldorf JA, Cohee LM, Ismail MD, Mathanga D, Cordy RJ, et al. High prevalence of Plasmodium falciparum gametocyte infections in school-age children using molecular detection: patterns and predictors of risk from a cross-sectional study in southern Malawi. Malar J. 2016;15:527. 
56. Walldorf JA, Cohee LM, Coalson JE, Bauleni A, Nkanaunena K, KapitoTembo A, et al. School-age children are a reservoir of malaria infection in Malawi. PLOS ONE. 2015;10:e0134061.

57. Lin E, Kiniboro B, Gray L, Dobbie S, Robinson L, Laumaea A, et al. Differential patterns of infection and disease with P. falciparum and P. vivax in young Papua New Guinean children. PLoS ONE. 2010;5:e9047.

58. Bhatt S, Weiss DJ, Cameron E, Bisanzio D, Mappin B, Dalrymple U, et al. The effect of malaria control on Plasmodium falciparum in Africa between 2000 and 2015. Nature. 2015:526:207-11.

59. Mullany LC, Lee Cl, Paw P, Shwe Oo EK, Maung C, Kuiper H, et al. The MOM Project: delivering maternal health services among internally displaced populations in eastern Burma. Reprod Health Matters. 2008;16:44-56.

60. Alemu A, Tsegaye W, Golassa L, Abebe G. Urban malaria and associated risk factors in Jimma town, south-west Ethiopia. Malar J. 2011;10:173.

61. Hiscox A, Khammanithong P, Kaul S, Sananikhom P, Luthi R, Hill N, et al. Risk factors for mosquito house entry in the Lao PDR. PLoS ONE. 2013;8:e62769.

62. Lwetoijera DW, Kiware SS, Mageni ZD, Dongus S, Harris C, Devine GJ, et al. A need for better housing to further reduce indoor malaria transmission in areas with high bed net coverage. Parasit Vectors. 2013:6:57.
63. Coleman M, Coleman M, Mabaso ML, Mabuza AM, Kok G, Coetzee M, et al. Household and microeconomic factors associated with malaria in Mpumalanga, South Africa. Trans R Soc Trop Med Hyg. 2010;104:143-7.

64. Liu JX, Bousema T, Zelman B, Gesase S, Hashim R, Maxwell C, et al. Is hous ing quality associated with malaria incidence among young children and mosquito vector numbers? Evidence from Korogwe, Tanzania. PLoS One. 2014;9:e87358.

65. Pinchoff J, Henostroza G, Carter BS, Roberts ST, Hatwiinda S, Hamainza $B$, et al. Spatial patterns of incident malaria cases and their household contacts in a single clinic catchment area of Chongwe District, Zambia. Malar J. 2015;14:305.

66. Hsiang MS, Hwang J, Tao AR, Liu Y, Bennett A, Shanks GD, et al. Mass drug administration for the control and elimination of Plasmodium vivax malaria: an ecological study from Jiangsu province, China. Malar J. 2013;12:383.

67. Cao J, Sturrock HJ, Cotter C, Zhou S, Zhou H, Liu Y, et al. Communicating and monitoring surveillance and response activities for malaria elimination: China's"1-3-7" strategy. PLoS Med. 2014;11:e1001642.
Ready to submit your research? Choose BMC and benefit from:

- fast, convenient online submission

- thorough peer review by experienced researchers in your field

- rapid publication on acceptance

- support for research data, including large and complex data types

- gold Open Access which fosters wider collaboration and increased citations

- maximum visibility for your research: over 100M website views per year

At BMC, research is always in progress.

Learn more biomedcentral.com/submissions 